\title{
3
}

\section{Assessing the Global Environment}

\author{
Matthew B. Myers \\ Antonio Borghesi
}

Ivan Russo

he current trend toward the globalization of supply chains renders many
managers confused as to what globalization really means. Often, the term is
little more than a battleground of semantics, of little value to the individual
tasked with managing value creation and cost reduction processes in the movement
of goods. Clearly, globalization infers the cross-border movement of goods and the
emergence of competitors and opportunities across competing supply chains
within an industry. Managers, however, often question the differences between a
global market and a single market, in that many of the same conditions exist in
both. Although this may be true, the complexities of cross-border operations are
exponentially greater than in a single country and the ability to compete in the
global environment is often dependent on understanding the subtleties that emerge
only in cross-border trade.
Descriptions of the global environment faced by supply chain managers have
been frequent, including an excellent summary by Nix (2001). Yet since 9/11, the
pressures on supply chain managers have intensified, given new security concerns
and the ensuing transportation delays that come with increased customs scrutiny,
coupled with previously existing political, cultural, and economic variance across
markets. This situation has contributed to the stress supply chains feel when trying
to meet delivery and service expectations, both at home and abroad. Perhaps not
coincidentally, the security crises arrived simultaneously with increased access to 
overseas labor, materials, and consumers. This dramatic exposure to both risk and return opportunities leads firms to face environmental challenges outside the realm of previously developed capabilities in supply chain management.

In this chapter, we discuss the environmental conditions influencing global supply chain decisions and effectiveness-for example, those conditions that need continuous assessment by managers. Most important, this discussion takes place in the context of a post-9/11 marketplace, where global supply chain management depends on effective manipulation of, and preparation for, increasingly volatile environmental conditions.

\section{Yesterday's Supply Chains in Today's Global Environment}

Given the enormous attention paid to supply chain activities over the past 15 years, it is not surprising that supply chain efficiencies, and even service offerings, have developed in multinational corporations. Unfortunately, the very characteristics that make supply chains cost-effective also make them vulnerable to the volatile global environment in which they exist. Both academics and consultants, such as A. T. Kearney (Monahan, Laudicina, and Attis 2005), note that just-in-time (JIT), automatic replenishment programs (ARP), and vendor-managed inventory (VMI) have reduced inventory levels to the bare minimum, with little or no safety stock. As a result, the recent outbreak of severe acute respiratory syndrome (SARS) in East Asia and the resultant disruptions in production in China caused auto manufacturing plants and computer assembly operations in the United States to shut down because of lack of parts and microchips. Sourcing from abroad means longer channels and lead times, as well as exposure to economic and political risks in the sourcing market. The current trend in outsourcing also leads to longer lead times and more middlemen, exposing firms to risk across multiple markets, as well as a loss of control over suppliers and third-party functionaries. Finally, the popularity of consolidating supply chain functions, by reducing the number of production and assembly facilities, suppliers, and middlemen, also exposes firms to increased risk from a less than diversified portfolio of partners. Although all these approaches have been effective in cost reductions, and are taught consistently in business schools, their application in a global context needs significant modification.

Although outside the control of managers, global supply chains are exposed to an increased number of technological and natural disasters that affect efficiencies and disrupt supply chain functions. For example, the Centre for Research on the Epidemiology of Disasters (2004) notes that technological disasters (those defined as industrial or transportation accidents) have increased exponentially worldwide over the past 30 years (see Figure 3.1). This should influence managers toward greater safety stock and other contingency efforts. But this has not been the case for most operations.

As a result of these "efficiency deficiencies," it is critical that the supply chain manager assess several aspects of the global environment capable of influencing 


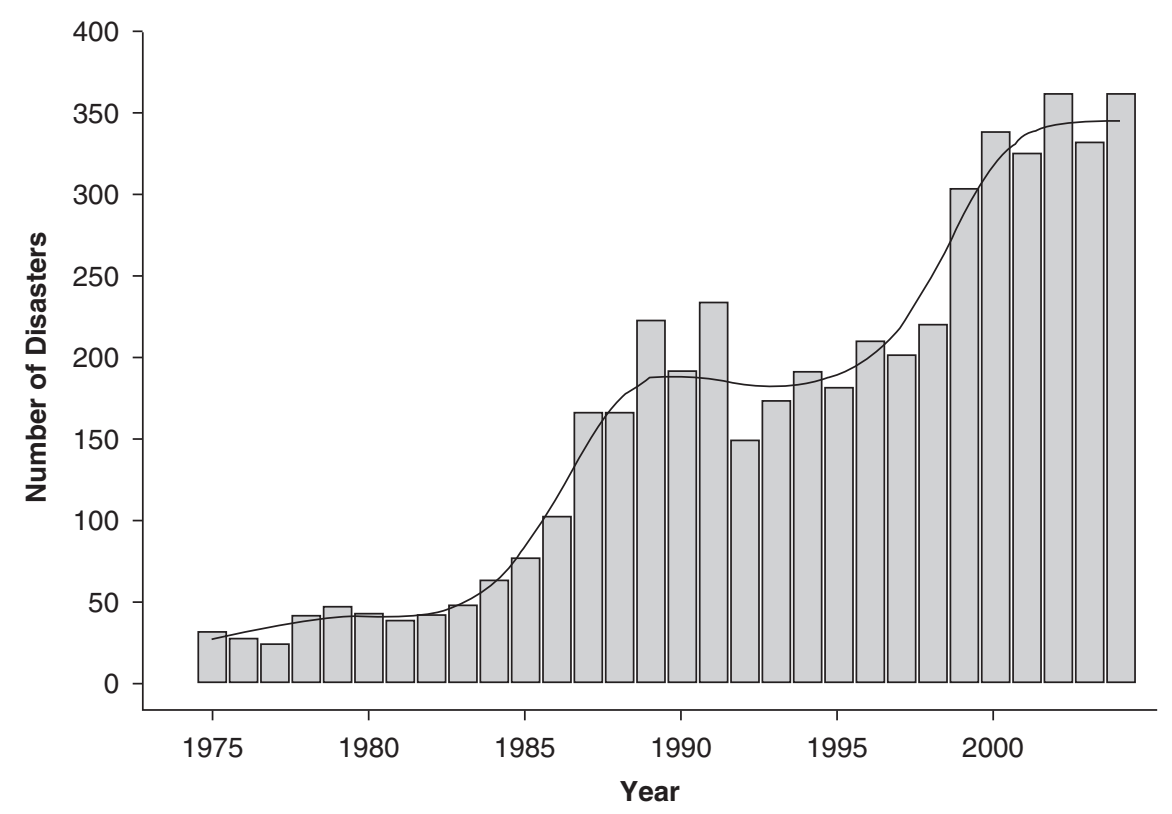

EM-DAT: The OFDA/CRED International Disaster Database: www.em-dat.net Université Catholique de Louvain, Brussels, Belgium

Figure 3.1 Total Number of Technological Disasters Reported Worldwide: 1975 to 2004

profitability and effectiveness. These variables, namely, the cross-cultural nature of supply chain management, foreign currency risk, security, and the political economy of markets, are specific to the global supply chain and often act to detrimentally affect an otherwise efficient operational strategy.

\section{Cross-Cultural Influences and the Global Supply Chain}

In today's supply chains, geographical distances between the partners are longer than in the past owing to firms seeking to take advantage of labor, raw materials, and tax differentials. These opportunities stimulate the organizations to expand and enlarge their supply chain across different countries. At the same time, competition demands a reactive and fast supply chain. Yet "globalization requires a highly coordinated flow of goods, information, and cash within and across national boundaries" (Bowersox and Calantone 1998, p. 86). For these reasons, many firms have decided to outsource their supply chain tasks abroad, where the cost of labor and raw materials is lower than in their home market. To globalize the supply chain is often ineluctable and requires the development of good relationships across 
multiple cultures. To choose a partner or a country solely based on labor cost is problematic as the best country for labor or raw materials could be the worst cultural match. The damages could be very serious if, for instance, a supplier or distributor will not share information, is apathetic regarding on-time delivery, or has significantly different ethical standards.

Each country has its specific elements of originality and peculiarity, and matching supply chain strategies with the different cultural imperatives is a challenge for every organization that decides to go abroad to do business. It is possible to develop an effective global supply chain design in every detail, yet a fit or match between culture and strategy is essential for strategy implementation and good performance. This means every firm should consider specific cultural aspects, such as ethnic, racial, political, and religious characteristics, for both supply chain partners and other entities within the market (Griffith and Myers 2005; Christie and Marshall 2001).

"Design and management of supply chain activities must consider the influence of differences in culture, industry structure, legal requirements, and infrastructure in different countries on customers, suppliers, competitors, and supply chain partners" (Zacharia 2001, p. 28). Culture, or the "collective programming of the mind which distinguishes the members of one group or category of people from another" (Hofstede 1991, p. 5), provides a society's characteristic profile with respect to norms, values, script, or sequences of appropriate social action, which affords an understanding of how societies manage relations (Schank and Abelson 1977; Triandis 1988; Bhawuk 2001; Hofstede 2001). Individuals operate based on their cultural orientation when engaging in business practice, for example, in negotiations (e.g., Brett and Okumura 1998).

One of the relevant issues in global supply chain relationships is how culturally founded norm expectations are embedded in bilaterally established relational norm governance strategies. Griffith and Myers (2005) developed a theoretical foundation for the influence of cultural norm expectations on relational strategies and focused on the cultural norm expectations driven by cultural theory and their implication and role in global supply chain management. The findings suggest that with the limited resources available to supply chain managers (time, manpower, etc.), firm performance is enhanced when supply chain processes such as information sharing and commitment levels are fit to culture-based norm expectations across culturally diverse relationships. In short, understanding the implications of the cultural variables affecting supply chain relationships results in better management of the global supply chain and the relationships between the partners.

Compatible corporate culture and management techniques of each organization in a supply chain are necessary for successful supply chain management (e.g., Cooper, Lambert, and Pagh 1997; Lambert, Stock, and Ellram 1998), and organizational compatibility is a prerequisite for creating a supply chain orientation in every firm of the network (Mentzer, Myers, and Cheung 2004). Thus, supply chain managers must focus on two important, yet related, aspects of culture: national and organizational. Pothukuchi et al. (2002) showed that differences in organizational culture are more significant in causing problems than differences in national culture and are more difficult to manage. 
A relational strategy incorporating intercultural issues encourages identification of supply chain partners that share a common vision and are pursuing parallel objectives to create structures and processes that improve cross-organizational behavior (Rodrigues, Stank, and Lynch 2004). "It can be argued that in today's challenging global markets, the route to sustainable advantage lies in being able to leverage the respective strengths and competencies of network partners to achieve greater responsiveness to market needs" (Christopher and Peck 2003, p. 121). Often, these strengths are in managing cross-cultural relationships.

\section{Foreign Currency Volatility}

Despite the consolidation of a number of currencies in recent decades, foreign currency volatility remains an important problem for supply chain managers (Christie and Marshall 2001). Failure to properly account for foreign currency changes the costs of businesses by hundreds of millions of dollars per year. Exchange risk is the change in the dollar, yen, or euro value of exposed assets or liabilities resulting from changes in the spot rate during a given period. Often, supply chain managers fail to realize their exposure to foreign currency swings when remittances are due in 90 , 120 , or 180 days. Depending on the size of the contract, a $1 \%$ change in currency value can lead to thousands of dollars (or euros, yen, etc.) in losses. Furthermore, the value of inventory held in foreign warehouses must be restated each reporting period when fluctuating exchange rates result in the recognition of an unrealized gain or loss. Adjustments for these gains and losses must be considered when restating data in foreign currencies.

Although it is a somewhat dramatic example, Table 3.1 indicates foreign currency fluctuations relative to the U.S. dollar for the week after September 11, 2001. In this instance, the tumble in the dollar value had significant effects on any outstanding contracts. For a firm that owed $\$ 100,000$ on September 17, 2001, at the end of a 30-day contract, the value of that payment fell precipitously against the major European and Japanese currencies.

Table 3.1 Foreign Currency Volatility and Supply Chain Exposure: Changes From 10 September - 17 September 2001

\begin{tabular}{lc}
\hline Currency & \% Change in U.S. Dollar Value \\
\hline French franc & -2.52 \\
German mark & -2.64 \\
Euro & -2.63 \\
Yen & -2.70 \\
Swiss franc & -4.85 \\
British pound & -0.41 \\
\hline
\end{tabular}

NOTE: At the time, both the euro and the individual country currencies were in circulation. 
In reality, the financial and accounting complexities of foreign exchange (FX) rates go beyond the understanding, or responsibility, of global supply chain managers. Instead, it is the task of managers to reduce FX risk in global supply chain transactions. The simplest method is to conduct transactions in the firm's home currency. Samiee and Anckar (1998) note that choice of foreign currency is often an important negotiating point in global supply chains. Interestingly, the use of foreign currencies was found to be positively related to sales volume and transaction value but negatively related to profitability. This is very likely due to an inability, or unwillingness, on the part of supply chain managers to hedge against possible FX changes while catering to partner desires regarding currency use. As a result, competitive supply chains have become adept at using hedging techniques or, at the very least, negotiating profitable terms relative to potential fluctuations.

\section{Political Economies}

Global supply chain designs must take into account changing political economy infrastructures to remain competitive. Political economies, in the form of regional economic integration, are agreements among countries in a geographic region to reduce, and ultimately remove, tariff and nontariff barriers to the free flow of goods, services, and factors of production among each other. Supply chain optimization mandates that firms take advantage of these trade arrangements to meet multiple market needs, or benefit from multiple market offerings, while reducing the overall costs associated with taxes, tariffs, and other trade barriers. Economic integrations run from the simple free flow of goods (free trade areas) to full political and economic integration (political unions), and their influence on supply chain operations varies as regulations change across types (see Table 3.2). Proper assessment of the political economy scenario often facilitates considerable savings in tariffs, as well as market opportunities. It is essential to evaluate political risk, credit risk, social risk, and market risk and minimize their effects through awareness of their impact and cost across global supply chains.

Often, the political economy forces firms to alter their supply chain designs. For example, China, by understanding the need of U.S. and Western European firms to have access to its enormous market, can leverage this to force multinationals to comply with strict local content and local labor requirements. As a result, instead of exporting directly to China, firms must enter joint venture relationships with Chinese businesses or locate their own wholly owned subsidiaries inside the Chinese market. This enables the use of Chinese labor and components, yet forces the firm to modify its supply chain significantly. The rationale behind this policy is more than simply a desire by local governments to increase employment and local business sales; it is also seen as an opportunity to absorb the process technologies of Western firms. As a result, maintaining barriers to private processes and technologies is often difficult, and many multinationals find themselves creating competitors in overseas markets. Yet the trade-off is difficult, because the increased emphasis on sales volume to combat compressed margins mandates access to large markets such as India and China. 
Table 3.2 Regional Integration and Supply Chain Options

\begin{tabular}{|c|c|c|}
\hline $\begin{array}{l}\text { Type of Regional } \\
\text { Integration }\end{array}$ & Regulations & Supply Chain Perspectives \\
\hline FTA $^{a}$ & $\begin{array}{l}\text { All barriers to trade of } \\
\text { goods and services are } \\
\text { removed; each country } \\
\text { can determine its own } \\
\text { trade policies relative to } \\
\text { nonmembers }\end{array}$ & $\begin{array}{l}\text { Potential benefit of importing } \\
\text { into low-tax market, } \\
\text { distributing across all affiliated } \\
\text { markets in FTA } \\
\text { Local production and warehouse } \\
\text { facilities serving multiple } \\
\text { markets tariff free }\end{array}$ \\
\hline Customs Union & $\begin{array}{l}\text { Same as FTA, except with } \\
\text { common external trade } \\
\text { policy }\end{array}$ & $\begin{array}{l}\text { Potential benefits from lowest- } \\
\text { tax import closed } \\
\text { Local production and warehouse } \\
\text { facilities serving multiple } \\
\text { markets tariff free }\end{array}$ \\
\hline Common Market & $\begin{array}{l}\text { Similar to Customs Union, } \\
\text { but factors of production } \\
\text { can move freely across } \\
\text { borders }\end{array}$ & $\begin{array}{l}\text { Labor and capital can be used in } \\
\text { multiple markets without } \\
\text { penalty }\end{array}$ \\
\hline Economic Union & $\begin{array}{l}\text { Similar to Common Market, } \\
\text { but now using one } \\
\text { currency, with } \\
\text { harmonization of tax } \\
\text { rates among members, } \\
\text { common monetary and } \\
\text { fiscal policy }\end{array}$ & $\begin{array}{l}\text { Reduced translation exposure to } \\
\text { currency fluctuations } \\
\text { Often, greater demand for use } \\
\text { of local content and local } \\
\text { labor when accessing these } \\
\text { markets; increased call for } \\
\text { local production and assembly }\end{array}$ \\
\hline Political Union & $\begin{array}{l}\text { Full integration both } \\
\text { economically and } \\
\text { politically }\end{array}$ & Same as Economic Union \\
\hline
\end{tabular}

a. Free Trade Area.

\section{Two Sets of Rules}

A frequent assertion among managers in Western Europe and the United States is that unfair trade practices make it difficult for firms from developed nations to compete with products from lower-cost developing markets. In fact, this is the case, in that the organizations that set trade regulations develop two sets of trade rules, one for developed and one for developing markets. The rationale behind the discrepancy between markets is that with the massive disequilibrium in wealth levels between the market categories, a method of enabling developing markets to compete on the world stage is to slacken the tax, tariff, and subsidy regulations for developing markets relative to their developed competitors. In this way, developing 
Table 3.3 Two Sets of Rules: GATTa_Uruguay Round Regulations for Agricultural Products, Developed Versus Developing Economies

\begin{tabular}{lcc}
\hline Tariffs & $\begin{array}{c}\text { Developed Countries: } \\
\text { 1996-2001 }\end{array}$ & $\begin{array}{c}\text { Developing Countries: } \\
\text { 1996-2004 }\end{array}$ \\
\hline $\begin{array}{l}\text { Average cut for all agricultural } \\
\text { products (\%) }\end{array}$ & -36 & -24 \\
Minimum cut per product (\%) & -15 & -10 \\
Domestic support & & -13 \\
Total AMS cuts per sector \\
$\quad$ from 1988 baseline) (\%)
\end{tabular}

a. General Agreement on Tariffs and Trade.

b. Aggregate measure of support.

nations can protect their own markets while at the same time shipping to higherpaying developed markets at a reduced tax and tariff. Using agricultural products as an example, it is evident that the World Trade Organization, in the General Agreement on Tariffs and Trade (GATT) talks of the Uruguay round, has set different regulations for developed versus developing economies (see Table 3.3). Not only are developing economies mandated to reduce taxes and subsidies to a significantly lower level than developed markets, they also have three more years to accomplish the task. In this manner, low-cost products from overseas often enter developed markets with ease, meaning that local producers have trouble competing.

From a global supply chain perspective, however, managers should see opportunities in these discrepancies. Besides offering developing economies an opportunity to benefit from reduced regulatory pressures, the system is designed to provide incentives to multinational firms to select suitable developing locations and conduct specific supply chain tasks in those locales. By conducting manufacturing, assembly and subassembly, distribution and warehousing, and other functions in these markets, developing economies can benefit from increased labor levels, technology transfer, and foreign direct investment. Simultaneously, global supply chain managers benefit from operating in countries with reduced tax burdens, gaining access to those markets as well as shipping from reduced-tax ports. Often, survival of firms within supply chains depends on the ability, or willingness, of supply chain managers to consider moving critical tasks abroad. 


\section{The New Environment of Hypersecurity}

Today's global supply chain environment is highly security conscious. Concerns have arisen over potential product tampering, manifest integrity, and the actual contents of containers and units moving through supply chain facilities around the world (Rinehart, Myers, and Eckert 2005). Global supply chain managers focus on security for two very good reasons: (1) fear of improper products being introduced into the supply chain and (2) concerns that not meeting security requirements will mean longer delays in customs processes. Longer delays could mean disruptions in customer production schedules, added costs, and, ultimately, higher prices on finished products. One of the more interesting tools to solve this problem is radiofrequency identification (RFID). Through the use of RFID, it is possible to have visibility of supply chain flows from the first manufacturer to the last customer.

The assessment of personal and organizational relationship characteristics that exist between global supply chain partners can help improve the efficiency and effectiveness of security efforts around the world. In fact, managers are more frequently demanding that their supply chain partners take significant steps to ensure security precautions are taken and that these partners have the capability to meet the strengthened security requirements (Mentzer et al. 2004). Often, partner choices are dictated by the ability to meet these new environmental conditions.

\section{Conclusions}

Research on the organization of multinational corporations has projected the emergence of complex, internally differentiated structures (Malnight 2001). Largely, these complex structures are the result of organizations, including supply chains, operating in increasingly complex external environments. The shift of the firm's strategic focus is outside its home market, with emphasis on emergent strategic opportunities associated with managing a network of dispersed worldwide operations (Malnight 2001; Kogut 1984).

Similar to the focus on the multinational company, investigating emerging global supply chain patterns and managerial techniques mandates an understanding of the discrepancies across markets and the environmental variables that influence, or should influence, strategic decisions. Effective management of supply chain relationships depends on the ability of managers to appropriately fit, or align, organizational elements with environmental opportunities and threats (Griffith and Myers 2005). Largely, these opportunities and threats to global supply chains result from cross-cultural, political, economic, and security-oriented phenomena.

Typically, operationally oriented supply chain managers see culture as an intangible, more relevant to marketers than to themselves. The lack of inclusion of culture in strategic designs is a noteworthy limitation given the demonstrated influence of culture on global supply chain management issues (Wacker and Sprague 1998). Unfortunately, little, if any, cross-cultural research has empirically examined relational and knowledge development resources in global supply chain settings. As 
a result, managers are left with little guidance in the applicability of cultural research to this domain.

Further, and more importantly for global supply chain management, while some inter-cultural supply chain research ... has been conducted, this research tends to consist of single country studies primarily conducted in the U.S., thus providing researchers little understanding of how firms from different cultures perceive the relational and knowledge development resources when operating in inter-cultural, global supply chain relationships. (Griffith, Myers, and Harvey 2005, p. 17)

It is abundantly clear that a clash of cultures can detrimentally affect supply chain performance (Christie and Marshall 2001).

To a far greater extent, management's ability to factor political and economic environmental conditions into their global supply chain models has been supported by meaningful research in these areas, particularly relative to handling foreign currency volatility, managing complex political economy arrangements, security issues, and trade law. However, these issues continue to be enormous challenges to supply chain managers. Often, regional trade groupings, tax and tariff regulations, and even currencies themselves may change during the development of a global supply chain design or strategy. Nonetheless, these environmental conditions must be considered when developing strategies. Yet these environmental conditions will continue to influence the effectiveness and profitability of supply chains and their entities as the number of multinationals grows.

Increasingly, firms have reduced options relative to manufacturing, supplying, assembling, and selling in their home markets. Raw material prices, wage rates, trade regulations, and market access mandate that to survive, firms and their supply chain partners must pursue opportunities overseas. The larger the portfolio of markets in which the supply chain operates, the greater the opportunities and, simultaneously, the greater the complexities and risks resulting from turbulent environmental conditions.

\section{References}

Bhawuk, Dharm P. S. (2001), "Evolution of Cultural Assimilators: Toward Theory-Based Assimilators," International Journal of Intercultural Relations, 25 (2), 141-163.

Bowersox, Donald J. and Roger J. Calantone (1998), "Executive Insight: Global Logistics," Journal of International Marketing, 6 (4), 83-93.

Brett, M. Jeanne and Tetsushi Okumura (1998), "Inter- and Intracultural Negotiation: U.S. and Japanese Negotiators," Academy of Management Journal, 41 (5), 495-510.

Centre for Research on the Epidemiology of Disasters (2004), EM-DAT: The OFDA/CRED International Disaster Database. Brussels, Belgium: Université Catholique de Louvain.

Christie, Eilidh and Andrew Marshall (2001), "The Impact of the Introduction of the Euro on Foreign Exchange Risk Management in UK Multinational Companies," European Financial Management, 7 (3), 11-15. 
Christopher, Martin and Helen Peck (2003), Marketing Logistics. Amsterdam: ButterworthHeineman.

Cooper, Martha C., Douglas M. Lambert, and Janus D. Pagh (1997), "Supply Chain Management: More Than a New Name for Logistics," The International Journal of Logistics Management, 8 (1), 1-14.

Griffith, David A. and Matthew B. Myers (2005), "The Performance Implications of Strategic Fit of Relational Norm Governance Strategies in Global Supply Chain Relationships," Journal of International Business Studies, 36 (3), 254-269.

Griffith, David A., Matthew B. Myers, and Michael A. Harvey (2005), “Global Supply Chain Management: Intra- and Inter-Cultural Influences on Relationship and Knowledge Development Resources," Working paper.

Hofstede, Geert (1991), Cultures and Organizations: Software of the Mind. London: McGrawHill.

Hofstede, Geert (2001), Culture's Consequences. Thousand Oaks, CA: Sage.

Kogut, Bruce (1984), "Normative Observations on the International Value-Added Chain and Strategic Groups,” Journal of International Business Studies, 15 (2), 151-167.

Lambert, Douglas M., James R. Stock, and Lisa M. Ellram (1998), Fundamentals of Logistics Management. Boston: Irwin/McGraw-Hill.

Malnight, Thomas W. (2001), "Emerging Structural Patterns Within Multinational Corporations: Toward Process-Based Structures," Academy of Management Journal, 44 (6), 1187-1210.

Mentzer, John T., Matthew B. Myers, and Mee Shew Cheung (2004), "Global Market Segmentation for Logistics Services,” Industrial Marketing Management, 33 (1), 15-21.

Monahan, Sean, Paul Laudicina, and David Attis (2005), "Supply Chains in a Vulnerable, Volatile World," Executive Agenda, 6 (3).

Pothukuchi, Vijay, Damanpour Fariborz, Choi Jaepil, Chen C. Chao, and Ho Seung Park (2002), "National and Organizational Culture Differences and International Joint Venture Performance," Journal of International Business Studies, 33 (2), 243-265.

Rinehart, Lloyd M., Matthew B. Myers, and James A. Eckert (2005), "Using Supply Chain Relationship Characteristics as a Basis for Setting Global Logistics Strategy in a Security Driven Environment," Supply Chain Management Review, 8 (6), 52-63.

Rodrigues, Alexandre M., Theodore P. Stank, and Daniel F. Lynch (2004), "Linking Strategy, Structure, Process, and Performance in Integrated Logistics," Journal of Business Logistics, 25 (2), 65-94.

Samiee, Saeed and Patrik Anckar (1998), "Currency Choice in Industrial Pricing: A Cross National Evaluation,” Journal of Marketing, 62 (July), 112-127.

Schank, Roger and Robert Abelson (1977), Script, Plans, Goals and Understanding: An Inquiry Into Human Knowledge Structure. Hillsdale, NJ: Earlbaum.

Triandis, Harry C. (1988), "Collectivism vs. Individualism: A Reconceptualization of a Basic Concept in Cross-Cultural Social Psychology," in Cross-Cultural Studies of Personality, Attitudes and Cognition, G. K. Verma and C. Bagley, eds. London: Macmillan, pp. 60-95.

Wacker, J. G. and L. G. Sprague (1998), "Forecasting Accuracy: Comparing the Relative Effectiveness of Practices Between Seven Developed Countries," Journal of Operations Management, 16 (2/3), 271-290.

Zacharia, Z. G. (2001), "What Is Supply Chain Management?" in Supply Chain Management, John T. Mentzer, ed. Thousand Oaks, CA: Sage, pp. 1-25. 
